\title{
Rolê no IF: um aplicativo em favor da inclusão e contra a evasão no Ensino Médio Integrado
}

\section{Rolê in IF: an application for inclusion and against evasion in Integrated High School}

\author{
Elisa Carmo Franco de Almeida \\ Instituto Federal de Educação, Ciência e Tecnologia do Sudeste de Minas Gerais \\ elisa.franco@ifsudestemg.edu.br \\ Alex Fernandes da Veiga Machado \\ Instituto Federal de Educação, Ciência e Tecnologia do Sudeste de Minas Gerais \\ alex.machado@ifsudestemg.edu.br \\ Paula Reis de Miranda \\ Instituto Federal de Educação, Ciência e Tecnologia do Sudeste de Minas Gerais \\ paula.reis@ifsudestemg.edu.br
}

\begin{abstract}
Resumo
Documentos institucionais comprovam que uma das causas de evasão no Ensino Médio Integrado (EMI) do Instituto Federal do Sudeste de Minas Gerais - Campus Rio Pomba é a falta de conhecimento sobre a identidade dos cursos da referida modalidade. Partindo deste fato, o presente estudo buscou validar a hipótese de que um aplicativo para dispositivos móveis voltado a alunos em potencial seria um aliado do Campus Rio Pomba na prevenção da evasão escolar. Tal pressuposto baseia-se na ideia de que, ao dialogar com as especificidades da faixa etária e promover o conhecimento sobre os cursos, o app favoreceria o engajamento e a inclusão antecipada dos adolescentes a quem o EMI se destina. Assim, o método de validação foi composto por revisão bibliográfica, estudo de experiências educacionais recentes com uso de tecnologia, além de resultados de entrevistas com estudantes adolescentes internos e externos ao Instituto Federal em questão. Confirmou-se, assim, o potencial deste tipo de produto educacional, conclusão que levou ao desenvolvimento de uma proposta de protótipo de aplicativo. Nele, são encontradas informações curriculares, imagens, vídeos e informações identitárias do EMI, além de recurso de interação entre público externo e alunos que já ingressaram na instituição. Acredita-se que a comunicação e a tecnologia são capazes de prevenir a evasão escolar e promover a aproximação entre o Campus Rio Pomba e adolescentes público-alvo da Educação Profissional e Tecnológica (EPT), ao incluir estes últimos precocemente no universo institucional e permitir maior criticidade $\mathrm{e}$ reflexão quanto a que curso escolher.
\end{abstract}

Palavras-chave: Tecnologia. Comunicação. Permanência. Educação Profissional e Tecnológica. 


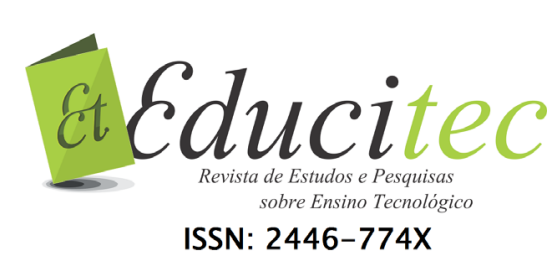

\section{Abstract}

Institutional documents prove that one of the causes of evasion in the Integrated High School (IHS) of the Federal Institute of Southeast Minas Gerais - Rio Pomba Campus is the lack of knowledge about the identity of the courses of this modality. Based on this fact, the present study sought to validate the hypothesis that a mobile application aiming at potential students would be an ally of the Rio Pomba Campus in preventing the school evasion. This assumption is based on the idea that, by dialoging with the specificities of the age group and promoting knowledge about the courses, the app would favor the engagement and early inclusion of the adolescents for whom the IHS is intended. Thus, the validation method consisted of literature review, study of recent educational experiences with the use of technology, and results of interviews with internal and external adolescent students at the Federal Institute in question. So, the potential of this type of educational product was confirmed, a conclusion that led to the development of an application prototype proposal. In it are found curriculum information, images, videos and identity information of IHS, as well as interaction feature between external public and students who have already joined the institution. It is believed that communication and technology are able to prevent dropout and promote rapprochement between the Rio Pomba Campus and teenagers targeted at Vocational and Technological Education (EFA), by including the latter early in the institutional universe and allowing greater criticality and reflection on which course to choose.

Key words: Technology. Communication. Permanence. Professional and Technological Education.

\section{INTRODUÇÃO}

A compreensão da evasão escolar perpassa um "vasto e intricado conjunto de circunstâncias individuais, institucionais e sociais" (DORE;LUSCHER, 2011, p.777). Sabe-se que ela é um processo complexo, dinâmico e cumulativo de desengajamento do estudante da vida da escola e, por isso, Dore e Luscher (2011) propõem como o encaminhamento mais adequado para o problema a prevenção.

Sabe-se também que a evasão afeta especialmente as classes populares, cujas chances de evadir-se são maiores, se comparadas às de níveis socioeconômicos mais altos (TINTO, 1975). E este é um agravante a ser necessariamente levado em conta pelos Institutos Federais, dada a função social destas entidades. Tal função está expressa em suas Diretrizes e Concepções (MEC, 2010) e, especificamente do Plano de Desenvolvimento Institucional do Instituto Federal do Sudeste de Minas Gerais (IF SUDESTE MG, 2014, p. 307), traduzida como um "claro compromisso institucional de empreender esforços para minimizar os efeitos das desigualdades sociais e regionais".

Pela natureza dos Institutos Federais, segundo a Lei $n^{\circ} 11.892$, de 29 de dezembro de 2008 (BRASIL, 2008, o Ensino Médio Integrado é uma modalidade prioritária e as taxas de evasão nesta forma de oferta costumam ser menores que nas demais: 


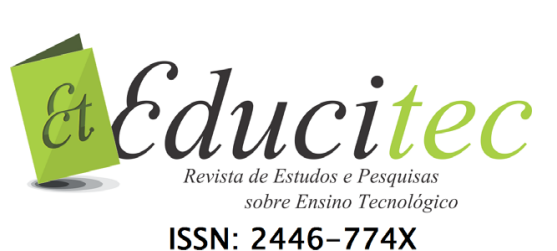

9,7\% era a média nacional registrada por estas instituições até o final do ano de 2018 (MINISTÉRIO DA EDUCAÇÃO, 2019). Mas no IF Sudeste MG - Campus Rio Pomba, os índices de evasão de três cursos do EMI mostram-se acima da média de seus pares:

a) Técnico em Alimentos, 7,8\%;

b) Técnico em Agropecuária, 20,9\%;

c) Técnico em Zootecnia, 10,5\%;

d) Técnico em Informática, 9,7\%;

e) Técnico em Meio Ambiente (oferta iniciada em 2017), 12,9\%.

As causas desse fenômeno na instituição já são conhecidas por meio de documentos institucionais (IF SUDESTE MG, 2016) e, com isso, sabe-se que a falta de conhecimento prévio sobre os cursos é uma delas. Assim, este estudo buscou não apenas compreender a referida falta de conhecimento, mas identificar de que maneira a instituição pode trabalhar a comunicação pública em prol da melhoria da relação com os adolescentes a serem atendidos no EMI, especialmente a fim de prevenir os abandonos na modalidade.

Primeiramente, faz-se necessário compreender por que a falta de conhecimento causadora de evasão no Campus Rio Pomba é um problema que passa pela comunicação pública - entendida aqui não apenas como aquela desenvolvida pelas instituições públicas, mas principalmente, como a comunicação que busca informar para o exercício da cidadania (BRANDÃO, 2009). Em seguida, é preciso identificar de que maneira a tecnologia revela-se aliada à permanência dos alunos no EMI. Assim, compõem este estudo três etapas: a primeira delas, documental, para compreensão do fenômeno da evasão no contexto específico do IF Sudeste MG e no que tange à Comunicação; uma segunda de revisão bibliográfica, com foco no comportamento adolescente e em experiências recentes nas quais pesquisadores utilizaram tecnologias de comunicação recentes com objetivos educacionais; e uma terceira fase, empírica, na qual resultados de entrevistas coletivas com adolescentes internos e externos à instituição em questão permitem confirmar, juntamente com os resultados das demais etapas, a hipótese de um aplicativo informativo e interativo possuir potencial para prevenir a evasão, considerando-se o contexto do EMI no Campus Rio Pomba. Por fim, é feita uma síntese do estudo, onde se propõe a materialização do aplicativo, como produto educacional capaz de ir ao encontro das necessidades comunicacionais identificadas ao longo da pesquisa É importante destacar que este trabalho também é parte do projeto de extensão, pesquisa e inovação, financiado pelo IF Sudeste MG, "Evasão no ensino médio integrado e comunicação pública: possibilidades a partir do diálogo e do conhecimento de identidades".

\section{Primeira fase: análise documental}

$\mathrm{Na}$ análise documental, estuda-se o principal documento ligado ao combate à evasão no IF Sudeste MG: o Plano Estratégico para a Permanência e Êxito dos Estudantes do IF Sudeste MG (PEPE) (IFSUDESTE MG - 2014). O PEPE é resultado de um estudo aprofundado de causas da evasão, realizado de forma 


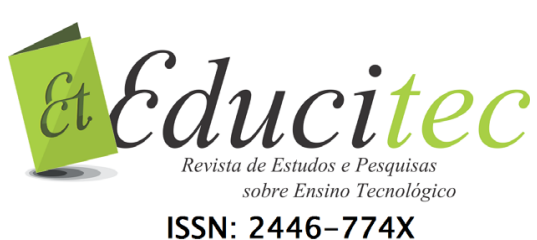

sistematizada em toda instituição e foi por meio dele que se identifica a principal razão de abandonos ocorridos especificamente no EMI do Campus Rio Pomba: a falta de conhecimento quanto à identidade dos cursos. Este estudo aponta uma série de causas para o problema da evasão, todavia, as conclusões a respeito do contexto em questão - ali resumidas em um parágrafo - descrevem especialmente uma tardia falta de identificação com os cursos. Segundo o documento,

\begin{abstract}
Quanto aos cursos técnicos integrados ao ensino médio: Zootecnia, Informática e Agropecuária, há muitos estudantes que manifestam, antes de desistir, que esperavam outro tipo de curso ou de carga horária, menos exigente $e$, ao não conseguirem se adaptar, pedem transferência para a rede estadual e abandonam o curso técnico por acreditar não serem capazes de acompanhar e serem aprovados no curso. Outro fator a destacar é que grande parte dos estudantes vêm de cidades distantes e a tenra idade (14/15 anos), aliada à distância de casa e dos pais, contribuem significativamente para o abandono do curso técnico integrado. (IF SUDESTE MG, 2016, p. 189, grifo nosso).
\end{abstract}

Identifica-se uma situação de frustração pós-ingresso, que dialoga com os apontamentos de Bardagi (2007, p. 34) os quais destacam que "os adolescentes parecem estar se comprometendo com escolhas profissionais sem realizar um processo exploratório amplo". A autora constata que inexiste, no Brasil, uma cultura de preocupação ou busca por informações que subsidiem a tomada de decisão destes jovens. Isto resulta em escolhas frágeis, nas quais o adolescente se expõe ao risco de frustração e, consequentemente, aumenta as próprias chances de evadir-se. Faz-se importante enfatizar que não se pretende, aqui, responsabilizar o aluno pelo referido contexto, mas apenas descrever um comportamento característico da faixa etária.

Ainda na fase diagnóstica do PEPE, foram analisados e organizados em categorias 33 questionários aplicados pelo próprio Campus a adolescentes evadidos do EMI. Apesar desse material não ter sido publicado pelo IF Sudeste MG, foi de grande importância para elaboração do PEPE e para a investigação que subsidiou este estudo. Ao debruçar-se sobre esses materiais, encontra-se, entre as respostas dos evadidos, a falta de identificação ou decepção com o curso escolhido como a razão mais frequente para o abandono da trajetória de estudos (24\%). Vale destacar, ainda, outro dado que reafirma a evasão como um fenômeno complexo e multicausal: quando solicitados a apontar programas institucionais que diminuem a evasão, nove dos 33 evadidos responderam: nada. E vários deles completam a questão com elogios, como: a escola já faz muito pra que os alunos não desistam. Surpreende também a quantidade de evadidos $(27 \%)$ que não respondeu a esta pergunta ou declarou não saber respondê-la. Juntos, os dois grupos correspondem a quase metade das respostas (48\%), evidenciando como os próprios evadidos têm dificuldades em apontar soluções e ações que instituição escolar poderia executar para promover a permanência.

Assim, na etapa documental deste estudo, constatou-se a necessidade de aproximação entre o IF Sudeste MG - Campus Rio Pomba e os adolescentes público-alvo do Ensino Médio Integrado. Existe um distanciamento entre as partes, ainda que seja verídica a informação do Campus já fazer muito pelos alunos. Nesse sentido, acredita-se que a Comunicação pode contribuir para minimizar as chances de abandono causados pela falta de conhecimento sobre os cursos, pois comunicar é construir pontes (CHINEM, 2006); comunicar é aproximar. 


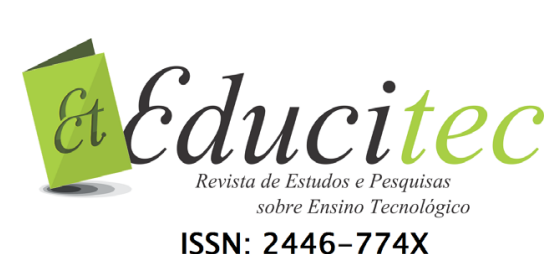

Justamente por ser a evasão um problema complexo, este estudo não preocupou-se em identificar responsáveis, mas apontar um caminho possível cuja iniciativa dependa essencialmente da instituição pública e sua comunicação com estudantes público-alvo da EPT. Entende-se que o conhecimento prévio sobre os cursos e sobre o universo do IF Sudeste MG coloca-se como requisito ao exercício da cidadania, ao permitir que os adolescentes sejam capazes de avaliar por si mesmos se desejam a proposta do EMI e do Campus Rio Pomba para suas próprias vidas. Ademais, em se tratando de uma instituição pública, a transparência ativa de informações é um dever (BRASIL, 2011). O IF Sudeste MG não o transgride (IF SUDESTE MG, 2010), ao disponibilizar, pelo site, as informações consideradas obrigatórias pela legislação. Contudo, o direito à comunicação dos indivíduos público-alvo da EPT vai além do estabelecido na Lei $n^{\circ}$ 12.527. Entre outros atributos, tem-se

acesso e pronta disponibilidade de informações públicas e governamentais, de modo abrangente, útil e rápido, especialmente no que concerne ao desenvolvimento e implementação de políticas e questões de interesse público (...) (INTERVOZES, 2005,s/p, grifo nosso).

Não há garantia de que as informações atualmente disponibilizadas pelo IF Sudeste MG sejam úteis, na visão do público a que se destina; de que sejam rapidamente acessíveis, ou ainda, de interesse dos adolescentes. A comunicação entre o Campus Rio Pomba e os adolescentes que virão a ser alunos do EMI requer um canal de comunicação capaz de favorecer a aproximação entre as partes, de maneira a incluir este público precocemente num universo institucional, universo esse que é de todos e deve ser conhecido em profundidade. Requer um canal que dialogue com características e anseios deste público, tornando tais adolescentes capazes de decidir, de forma crítica e reflexiva, sobre o próprio futuro e da sociedade.

\section{Segunda fase: um estudo sobre adolescentes $e$ as novas tecnologias}

Considera-se adolescente a pessoa entre 12 e 18 anos de idade (BRASIL, 1990) e é comum os sujeitos desta faixa etária serem vistos como um "problema" (LIMA, 2004, p. 94). Mas este estigma pode significar um empecilho à valorização das potencialidades de cada um deles enquanto educandos. Assim, Frigotto (2004) aponta a empatia como um caminho para os educadores: pensar a política de ensino médio partindo dos próprios sujeitos adolescentes - seus interesses, suas dificuldades, seus sonhos.

Diagnosticada a ausência de comportamento exploratório pelo público ingressante do Campus Rio Pomba, faz-se necessário conhecer que tipos de canais e mídias estes adolescentes utilizam e consideram atrativos, para que seja possível estabelecer comunicação e promover o conhecimento. E não se trata da comunicação em via de mão única - "como se os cidadãos fossem meros objetos de comunicados" (DUARTE, 2007) - mas sim de interatividade. Trata-se da comunicação descrita por Duarte $(2007$, p. 68$)$ como aquela que "diz respeito à criação de formas de acesso e participação". 


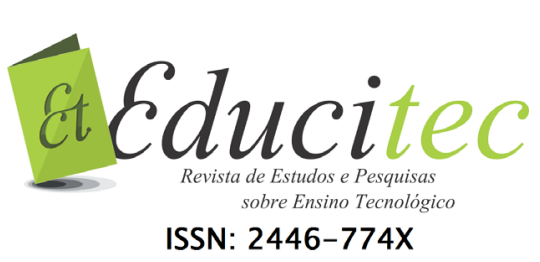

A interação, atualmente, é amplamente facilitada pelas Tecnologias de Informação e Comunicação (TICs), já incorporadas à vida moderna e necessárias para agilizar um "cotidiano imediatista" (SABOIA et al., 2013). Vive-se a chamada Era do Conhecimento, na qual a tecnologia

\begin{abstract}
possibilita a expressão de novas atividades, novos formatos de interação social, ampliação dos locais, formatos e estrutura do processo de ensino e aprendizagem, ampliando a percepção da sala de aula e da interação aluno-professor e aluno-aluno, adequando-a a necessidade do mercado (SABOIA et al., 2013, p. 3).
\end{abstract}

Nesse sentido, os produtos e serviços ligados aos smartphones, unindo características como instantaneidade e portabilidade, apresentam enorme potencial de captarem atenção da faixa etária aqui estudada. Pesquisa divulgada em setembro de 2018 pelo Comitê Gestor da Internet no Brasil - a TIC Kids Online (CRESCE, 2018) -, observou um crescimento no uso de dispositivos móveis entre crianças e adolescentes para acessar a Internet. Se em 2012, 21\% acessaram a rede por meio do celular, em 2017 são 93\%, o que representa 23 milhões de crianças e adolescentes. A pesquisa estima ainda que, em 2017, $44 \%$ das crianças e adolescentes usuários de Internet acessaram a rede exclusivamente por meio de telefones celulares, o que representa 11 milhões de jovens. Segundo essa pesquisa, - celular é o principal meio de acesso para crianças e adolescentes da área rural $(57 \%)$, do Norte $(59 \%)$ e classe DE $(67 \%)$.

É importante lembrar que o público do EMI é composto integralmente por "nativos digitais" (SABOIA et al., 2013, p. 3), pessoas que já incorporam dispositivos móveis como uma extensão do lar ou do seu próprio corpo. A esse respeito Saboia et al. (2013) citam como como principais preferências desses jovens: informações rápidas e de múltiplas fontes; som e vídeo, ao invés de texto; interação simultânea com muitas pessoas; e aprendizagem de coisas relevantes, instantaneamente úteis, lúdicas e divertidas. Experiências recentes confirmam tais apontamentos, como indica a subseção a seguir.

\title{
Experiências recentes
}

Relatos de experiências (ALENCAR et al., 2015; SILVA, 206; SILVA, 2018) comprovam que os smartphones podem ser de grande valia na Educação e na aproximação entre as instituições educacionais e adolescentes público-alvo do EMI. Tais recursos tecnológicos não devem ser vistos, portanto, como inimigo dos professores e das escolas, mas como fortes aliados da educação, inclusive no combate à evasão escolar.

Alencar et al (2015) demonstraram que a interatividade do aplicativo de mensagens WhatsApp pode ser de grande valia no desenvolvimento do fazer pedagógico:

é uma ferramenta extremamente útil para comunicação entre pessoas em espaços físicos diferentes, e que no contexto educacional pode ser uma ótima ferramenta se mediada por alguém, seja professor ou tutor, que direcione o sentido dos grupos e conversas" (ALENCAR et al., 2015, p. 793).

De forma similar, Silva (2016) propôs uma plataforma educacional de avaliação, acessível por aplicativos para smartphones ou tablets, para que estudantes de 


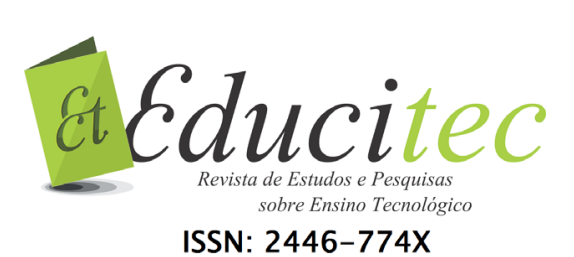

cursos superiores pudessem comunicar à instituição, em tempo real, indicativos de reordenação capazes de levar à construção do sucesso no processo de ensino e aprendizagem. O pesquisador concluiu que, por meio da plataforma, a instituição estudada foi capaz de explorar o perfil do aluno e suas demandas, direcionando a estes um tratamento específico capaz de ampliar o sentimento de fidelidade com a IES. "E, assim, [este aluno] dificilmente irá evadir, mantendo a continuidade do processo educacional e pedagógico" (SILVA, 2016, p. 73).

Explorando também a interatividade conectada e a participação adolescente, Silva (2018) utilizou o Facebook como ferramenta de interação no ensino de Informática, com o objetivo de reduzir a evasão escolar. Para o autor, as redes sociais são um fator de motivação, agregando um caráter lúdico às experimentações e promovendo a "associação do encanto ao conhecer" (SILVA, 2018, p. 91). Ele destaca também como resultados a melhoria da comunicação e a aproximação da escola com os alunos, objetivos dos quais se compartilha neste estudo.

Tratando especificamente de experiências com aplicativos em Institutos Federais, identifica-se o uso desta tecnologia pelo Instituto Federal do Sergipe, instituição que permite a seus alunos o acesso a diversas informações acadêmicas usando apenas o celular (IFS DIGITAL, 2018).

Já a criação de um aplicativo para pessoas que ainda não fazem parte da instituição é uma proposta que parece ser inédita. No Banco Internacional de Objetos Educacionais $^{1}$ não foram encontrados produtos similares à proposta em questão. Nota-se, ao contrário, uma recorrência de aplicativos voltados ao estudante, com facilidades de acesso a notas, informações sobre eventos, entre outros, mas nenhuma tecnologia interativa similar voltada ao candidato em potencial.

Contudo, a aposta na interação com estudantes que ainda não fazem parte da instituição escolar, com o objetivo de prevenir-se a evasão, relaciona-se às teorias de Tinto (1975), para quem o engajamento é um fator de permanência. Aproximar alunos em potencial é uma ação que pode ser compreendida como a antecipação deste engajamento. Ao disponibilizar o aplicativo e buscar se aproximar dos alunos em potencial, a instituição estaria também antecipando um vínculo, permitindo que o estudante se identifique - ou não - com sua proposta e seus cursos. Favorecendo o exercício da autonomia e reflexão, além do comportamento exploratório, um aplicativo voltado a adolescentes externos também seria capaz de favorecer o exercício da cidadania, evitando ou minimizando as frequentes investidas em trajetórias que podem não representar os verdadeiros anseios dos estudantes em nível médio.

\section{Terceira fase: diálogos com adolescentes ligados ao contexto do Campus Rio Pomba}

Apesar do forte indicativo de que um aplicativo para smartphone seria capaz de auxiliar na comunicação entre o Campus Rio Pomba e seus futuros alunos, fez-se necessária não apenas confirmação empírica voltada ao microuniverso regional do contexto estudado, mas também a descoberta do como funcionaria esta tecnologia. 


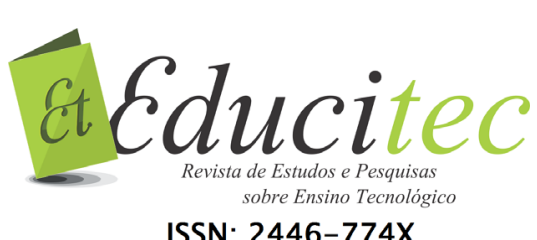

ISSN: $2446-774 X$

Assim, na segunda fase deste estudo, foram feitas entrevistas coletivas com dois grupos de estudantes: a primeira, com a turma do $1^{\circ}$ ano do curso técnico integrado em Agropecuária; e a segunda, com um grupo de adolescentes externos ao IF Sudeste MG, participantes de um projeto social da Prefeitura Municipal de Rio Pomba. As respostas, interpretadas através do método de análise de conteúdo à luz de Bardin (2011), mostram-se ricas em informações e levam a diversas conclusões. Entretanto, no presente trabalho, foi necessário resumir tal processo conforme objetivos específicos de divulgação.

$\mathrm{Na}$ primeira entrevista, feita com alunos do $1^{\circ}$ ano do Técnico Integrado em Agropecuária do IF Sudeste MG - Campus Rio Pomba, buscou-se identificar as características formadoras da identidade do IF Sudeste MG - Campus Rio Pomba e do curso de Agropecuária, para que fosse possível, futuramente, promover o conhecimento sobre ambos. Os estudantes também foram questionados sobre suas experiências no momento anterior ao ingresso para identificar-se que tipo de conhecimento Ihes fez falta naquele momento. Eles foram, ainda, chamados a se manifestar quanto à necessidade e à eficácia de um possível aplicativo que ajudasse a incluir candidatos antecipadamente no universo onde eles já estão inseridos e demonstraram aprovação.

Quanto à maneira como se informaram antes de ingressar, verificou-se que as informações oficiais, emitidas pela instituição, ficam em segundo plano nas escolhas dos alunos, em relação ao marketing de referência, popularmente conhecido como boca a boca. Ademais, segundo eles, a maioria das informações que os estudantes recebem e absorvem não corresponde à identidade da instituição e do curso. Percebeu-se também que há diversas características do curso e do Campus que provocam surpresa dos alunos após o ingresso, como a variedade de disciplinas, a existência de aulas práticas e a estrutura física. Os alunos concordam que estas e outras características, positivas ou negativas, devem ser antecipadas a que busca ingressar no curso, pois esta antecipação seria uma ferramenta capaz de minimizar a evasão. Os problemas de comunicação estão frequentemente evidenciados na fala dos entrevistados e a ausência de comportamento exploratório e de conhecimento prévio sobre o curso fica evidente em diversos momentos, como na fala de uma das alunas: eu vim pra cá sem saber pra onde eu tava vindo. Juro.

Assim, de fato, existe a necessidade do Campus se fazer mais presente na comunidade, em especial junto aos adolescentes público-alvo do EMI, pois os atuais meios de comunicação utilizados não são suficientes para promover conhecimento quanto à realidade institucional. Faz-se necessário um novo canal ou, no mínimo, a revisão dos atuais. Os mesmos alunos demostram predisposição em colaborar na construção de um eventual aplicativo para celular com a função de expor a realidade da instituição, promover conhecimento sobre os cursos do Campus Rio Pomba e esclarecer dúvidas dos ingressantes.

Já na segunda entrevista, o objetivo era verificar se um aplicativo para celular voltado a candidatos do IF Sudeste MG teria chances de ser utilizado por estudantes público-alvo da EPT. Verificou-se que os 20 adolescentes participantes, com idade entre 14 e 17 anos, atendidos pela Prefeitura Municipal de Rio Pomba por sua situação de vulnerabilidade social, possuíam celulares com acesso à internet e que havia interesse em conhecer melhor a instituição e seus cursos. Os entrevistados foram incitados a dizer o que lhes ocorre à mente quando o assunto é Instituto 


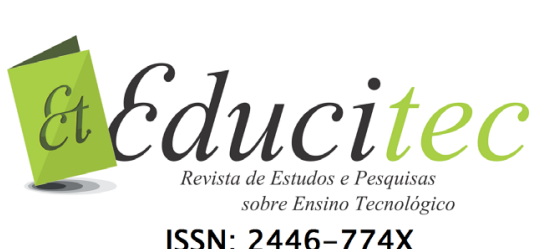

Federal, para que as pesquisadoras identificassem algo sobre a imagem institucional. Esta se mostrou positiva. Exemplo: a minha prima estudou lá e falou que era bom. Porém, esta vantagem não parece superar a ideia de dificuldade de ingressar e de se manter nos cursos. Exemplo: vem na minha cabeça que eu não vou nunca pra lá não, que é muito difícil.

Novamente, a comunicação institucional oficial aparece em segundo plano em relação ao boca-a-boca (fulano me disse), levando a crer que esta primeira comunicação precisa ser repensada. A situação indica também que a comunicação feita pela instituição poderia explorar as vantagens do IF Sudeste MG, pois informalmente elas já são reconhecidas como pontos positivos e são de interesse do público-alvo.

Vale lembrar que muitas características identitárias do Campus Rio Pomba e do curso de Agropecuária foram mencionados como positivas na primeira entrevista com alunos do IF Sudeste MG -, como o desenvolvimento da autonomia e as múltiplas possibilidades de carreira, e portanto, podem ser trabalhadas numa nova Comunicação de utilidade pública.

Após essa aproximação, foram apresentadas aos entrevistados as possíveis funcionalidades previamente pensadas para o aplicativo com base na literatura (TINTO, 1975; BARDAGI, 2007; BRANDÃO;CARVALHO, 2007), o grupo demonstrou aprová-las, com ênfase especial na interatividade: a possibilidade de conversar com adolescentes que já estão vivendo a experiência de ser aluno do IF Sudeste MG.

Pelo estudo deste caso, em particular, confirma-se o potencial de um aplicativo para smartphone que busque promover conhecimento sobre os cursos e aproximação do Campus Rio Pomba com alunos em potencial. Com base na literatura e na experiência empírica, propõe-se, portanto, o produto educacional detalhado a seguir.

\title{
Rolê no IF: um produto comunicacional em favor do EMI no Campus Rio Pomba
}

Apresenta-se, nesta seção, a proposta de um aplicativo para dispositivo móvel elaborada com base na literatura, no estudo documental e na experiência empírica que compuseram este estudo. Optou-se por organizar as funcionalidades desse aplicativo em um quadro, de maneira a evidenciarmos os fundamentos que as justificam, bem como ampliar as chances do leitor idealizar este produto. De uma maneira geral, a disponibilização do aplicativo justifica-se nas teorias de autores como Bardagi (2007, p. 17), para quem a escola, especificamente, deve promover um espaço no qual o aluno possa:

\begin{abstract}
conhecer, de modo progressivo e gradual, a realidade do mundo do trabalho no qual ingressará e os vínculos entre os indivíduos e as ocupações; desenvolver estratégias de busca de informações e tomada de decisões; e experimentar, na prática cotidiana, a sensação de ser uma pessoa cada vez mais autônoma, capaz de definir e solucionar problemas e construir seu projeto vocacional .
\end{abstract}

As diretrizes de Bardagi (2007), assim como de outros autores aqui citados, orientaram a criação de telas e conteúdos que compõem a proposta de aplicativo e 
ISSN: $2446-774 X$

encontram-se descritos no Quadro 1. Não detalha-se, neste trabalho, o formato e o aspecto visual do software, pelo fato desta etapa merecer a atenção de um estudo específico à parte.

O aplicativo foi denominado Rolê no IF, como forma de designar, em linguagem coloquial, um passeio virtual e despreocupado pela instituição. Seu objetivo é promover o conhecimento sobre os cursos do EMI, dialogando com o público-alvo desta modalidade (Figura 1)

Figura 1 - Tela de abertura do aplicativo Rolê no IF

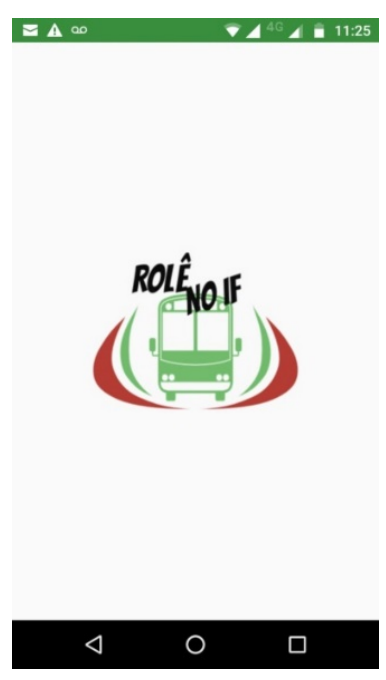

Fonte: Aplicativo Rolê no IF (autoria própria)

Ao utilizar o Rolê no IF pela primeira vez, o usuário será convidado a fazer login usando sua conta do Facebook, poupando-lhe tempo de cadastro e permitindo a comunicação e o compartilhamento de informações em geral entre o aplicativo e a rede social. Em seguida, será conduzido a responder um quiz, no qual será feita uma série de perguntas sobre preferências pessoais. As respostas são associadas a características dos cursos técnicos integrados do Campus Rio Pomba Agropecuária, Alimentos, Meio Ambiente, Informática e Zootecnia - conforme as habilidades normalmente exigidas ou desenvolvidas em cada um deles (Figuras 2 e 3).

Figura 2 - Tela inicial da função Quiz do aplicativo Rolê no IF 
ISSN: $2446-774 X$

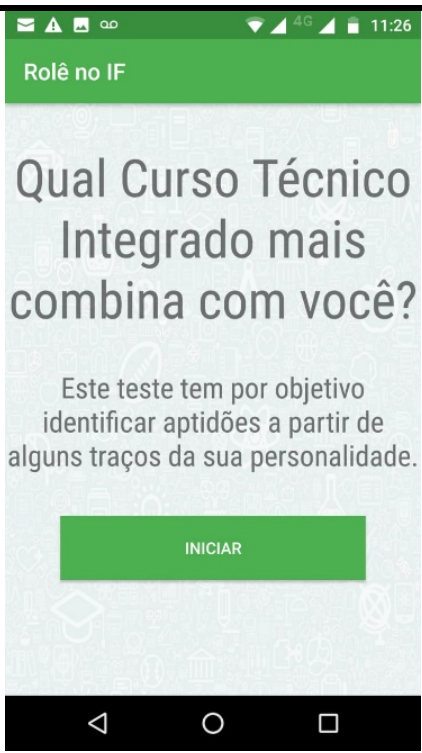

Fonte: Aplicativo Rolê no IF (autoria própria)

Figura 3 - Exemplo de tela de execução da função Quiz do aplicativo Rolê no IF

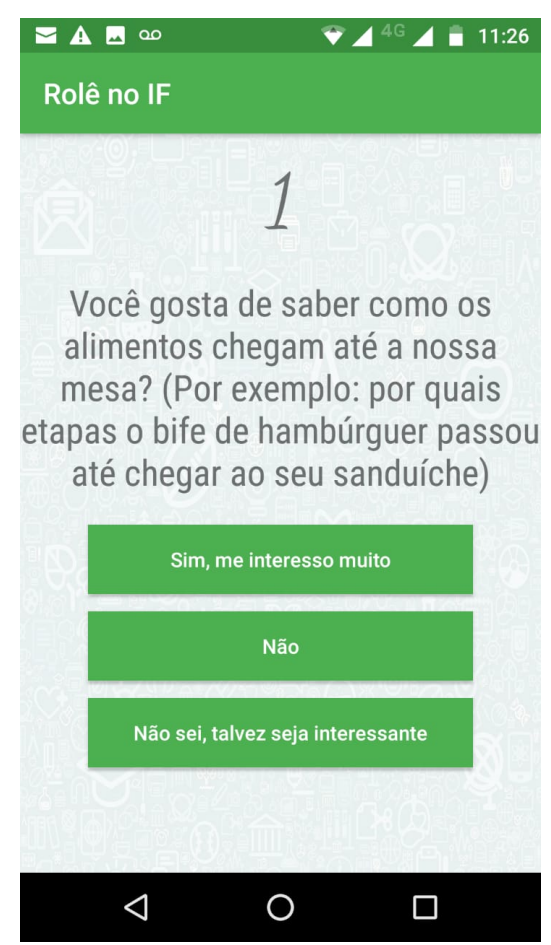

Fonte: Aplicativo Rolê no IF (autoria própria)

As perguntas do quiz foram elaboradas e propostas pelos pesquisadores, após o diálogo com psicólogas da instituição, pesquisa sobre os cursos e validação com adolescentes estudantes do EMI no Campus Rio Pomba. O usuário terá como resultado do quiz uma sugestão de curso, supostamente compatível com seu gosto e com as características pessoais informadas. levado a conhecer melhor sobre a profissionalização ali sugerida. Este resultado poderá ser compartilhado no Facebook. Então, após ser apresentada uma breve descrição textual daquele curso, 
ISSN: $2446-774 X$

o adolescente deverá explorar as demais funções não textuais do aplicativo (Quadro 1).

Quadro 1 - Funcionalidades e justificativas de funções do aplicativo Rolê no IF

\begin{tabular}{|c|c|c|}
\hline Nome & Função & Justificativa \\
\hline Quiz & $\begin{array}{l}\text { Usar as preferências } \\
\text { pessoais do candidato } \\
\text { para sugerir um ou dois } \\
\text { entre os cinco cursos do } \\
\text { EMl. Apoiar de maneira } \\
\text { direta a escolha de um } \\
\text { curso. }\end{array}$ & $\begin{array}{l}\text { - O quiz busca não apenas despertar } \\
\text { a curiosidade dos adolescentes pelo } \\
\text { resultado desconhecido, mas } \\
\text { oferecer apoio personalizado, ou } \\
\text { seja, sugerir um curso levando em } \\
\text { consideração a individualidade do } \\
\text { estudante. }\end{array}$ \\
\hline Tour virtual & $\begin{array}{l}\text { Simular a visitação ao } \\
\text { Campus, apresentando ao } \\
\text { aluno em potencial } \\
\text { imagens em } 360^{\circ} \text { dos } \\
\text { ambientes de formação e } \\
\text { socialização. }\end{array}$ & $\begin{array}{l}\text { - Com base nas teorias de Tinto } \\
\text { (1975) e Bardagi (2007), realidade e } \\
\text { identidade dos cursos devem ser } \\
\text { antecipadas a quem deseja ingressar } \\
\text { neles; } \\
\text { - as entrevistas com alunos internos } \\
\text { e externos ao IF Sudeste MG } \\
\text { confirmam a validade dessa } \\
\text { antecipação de elementos } \\
\text { identitários; } \\
\text { - a entrevista com alunos externos } \\
\text { também mostra a existência de } \\
\text { rejeição ao formato textual, por isso } \\
\text { se aposta em recursos de imagem } \\
\text { como o tour e os vídeos; } \\
\text { - acredita-se que a inserção virtual no } \\
\text { ambiente pode ampliar } \\
\text { familiarização do estudante com o } \\
\text { Campus, favorecendo a inclusão } \\
\text { prévia; alunos externos demonstraram } \\
\text { - alunos a } \\
\text { interesse nesta funcionalidade. }\end{array}$ \\
\hline $\begin{array}{l}\text { Matérias/ } \\
\text { Disciplinas }\end{array}$ & $\begin{array}{l}\text { Informar, por meio de lista } \\
\text { simples, de maneira } \\
\text { objetiva e direta, quais } \\
\text { serão as disciplinas } \\
\text { estudadas em cada etapa } \\
\text { do curso. }\end{array}$ & $\begin{array}{l}\text { - as entrevistas com alunos externos } \\
\text { e internos ao IF Sudeste MG } \\
\text { confirmam a validade da antecipação } \\
\text { de elementos identitários; } \\
\text { - o site da instituição não oferece } \\
\text { acesso direto a esta relação, o que } \\
\text { pode ser um fator de distanciamento; } \\
\text { - alunos internos demonstraram que } \\
\text { gostariam de ter tido acesso a estas }\end{array}$ \\
\hline
\end{tabular}


ISSN: 2446-774X

\begin{tabular}{|c|c|c|}
\hline & & $\begin{array}{l}\text { informações e demonstraram } \\
\text { desconhecimento quanto à } \\
\text { possibilidade de acessá-las no site; } \\
\text { - alunos externos ao IF sudeste MG } \\
\text { demonstraram interesse em } \\
\text { conhecer as disciplinas a serem } \\
\text { cursadas durante o curso. }\end{array}$ \\
\hline Depoimentos & $\begin{array}{l}\text { Disponibilizar depoimentos } \\
\text { reais, produzidos por } \\
\text { alunos e ex-alunos, em } \\
\text { formato de vídeo } \\
\text { (preferencialmente) ou } \\
\text { pequenos parágrafos. } \\
\text { Oferecer a possibilidade } \\
\text { de contato entre os } \\
\text { usuários do aplicativo e os } \\
\text { depoentes (vide função } \\
\text { Chat). }\end{array}$ & $\begin{array}{l}\text { - Esta função se justifica por criar } \\
\text { identidade e aproximações entre } \\
\text { público-alvo, estudantes e egressos. } \\
\text { Valoriza as informações que já } \\
\text { demonstraram largo alcance } \\
\text { enquanto marketing de referência - } \\
\text { ou boca a boca. Tem mais chances } \\
\text { de aproximar os estudantes externos } \\
\text { da instituição devido à similaridade } \\
\text { entre interlocutores que se } \\
\text { encontram na mesma faixa etária. }\end{array}$ \\
\hline $\begin{array}{l}\text { Seis coisas } \\
\text { que você } \\
\text { precisa saber }\end{array}$ & $\begin{array}{l}\text { Antecipar, por meio de } \\
\text { vídeos descritivos em } \\
\text { linguagem informal, } \\
\text { aspectos da identidade do } \\
\text { curso e do Campus Rio } \\
\text { Pomba, incluindo-se } \\
\text { aqueles que podem ser } \\
\text { vistos como negativos. }\end{array}$ & $\begin{array}{l}\text { - Segundo Bardagi (2007, p. 61), } \\
\text { "antecipar a ocorrência de um evento } \\
\text { estressante permite que se inicie um } \\
\text { processo preparatório que reduz os } \\
\text { efeitos nocivos do acontecimento"; } \\
\text { - alunos internos ao IF Sudeste MG } \\
\text { apontaram espontaneamente que } \\
\text { antecipar desafios seria capaz de } \\
\text { reduzir a evasão causada pela falta } \\
\text { de identificação. }\end{array}$ \\
\hline Carreira & $\begin{array}{l}\text { Apresentar, por meio de } \\
\text { vídeos e texto, a realidade } \\
\text { do mundo do trabalho no } \\
\text { qual o futuro profissional } \\
\text { ingressará e os vínculos } \\
\text { entre os indivíduos e as } \\
\text { ocupações. }\end{array}$ & $\begin{array}{l}\text { - Bardagi (2007) destaca a } \\
\text { importância de salientarem-se as } \\
\text { dimensões emocionais positivas do } \\
\text { trabalho; ela também aponta a } \\
\text { necessidade de possibilitar aos } \\
\text { adolescentes uma conexão entre a } \\
\text { profissão e a experiência do curso, } \\
\text { pelo fato da primeira parecer muito } \\
\text { distante; } \\
\text { - com base em Tinto (1975), } \\
\text { podemos concluir que criar } \\
\text { expectativas positivas e motivadoras } \\
\text { favorece o engajamento com o curso. }\end{array}$ \\
\hline $\begin{array}{l}\text { Agendamento } \\
\text { de visita }\end{array}$ & $\begin{array}{l}\text { Oferecer, por meio de um } \\
\text { formulário simples, um } \\
\text { canal de agendamento de } \\
\text { visita ao Campus; }\end{array}$ & $\begin{array}{l}\text { - necessidade de diminuir o } \\
\text { distanciamento entre o IF Sudeste } \\
\text { MG - uma instituição pública - e a } \\
\text { comunidade externa, facilitando o }\end{array}$ \\
\hline
\end{tabular}


ISSN: $2446-774 X$

\begin{tabular}{|c|c|c|}
\hline & $\begin{array}{l}\text { demonstrar que o } \text { IF } \\
\text { Sudeste MG está aberto a } \\
\text { receber } \\
\text { interessado em conhecer a } \\
\text { instituição. }\end{array}$ & $\begin{array}{l}\text { acesso ao seu interior e favorecendo } \\
\text { a avaliação crítica quanto ao que ela } \\
\text { oferece. } \\
\text { - Nas entrevistas os alunos externos } \\
\text { ao IF Sudeste MG demonstraram } \\
\text { interesse nesta funcionalidade. }\end{array}$ \\
\hline Chat & $\begin{array}{l}\text { Oferecer aos usuários do } \\
\text { aplicativo a possibilidade } \\
\text { de clicar na imagem dos } \\
\text { alunos depoentes e } \\
\text { conversar diretamente } \\
\text { com eles, sanando } \\
\text { dúvidas e curiosidades, } \\
\text { com pessoas que já vivem } \\
\text { ou viveram a experiência } \\
\text { do curso. }\end{array}$ & $\begin{array}{l}\text { - Para Brandão \& Carvalho (2007), a } \\
\text { comunicação moderna tem de ser } \\
\text { ágil e informal. Ressaltam a } \\
\text { importância de acontecer ao vivo e, } \\
\text { principalmente, de ser legítima, } \\
\text { verdadeira, algo que pode ser } \\
\text { alcançado valorizando o público } \\
\text { interno de uma organização; } \\
\text { - entrevistados externos ao IF } \\
\text { Sudeste MG demonstraram interesse } \\
\text { especial por esta funcionalidade. }\end{array}$ \\
\hline
\end{tabular}

Fonte: Arquivo dos pesquisadores

Assim como nas experiências similares vivenciadas por outros autores (ALENCAR et al., 2015; SILVA, 206; SILVA, 2018), a dinâmica de alimentação será baseada na interatividade. A ideia é que os próprios alunos do IF possam inserir seus depoimentos e avaliar os cursos que estão fazendo e, de forma complementar, poderão responder dúvidas de quem está interessado em ingressar. Embora não seja esse o objetivo do aplicativo, gestores poderão tomar conhecimento das avaliações para identificar e solucionar problemas pontuais. Obviamente, a manutenção do aplicativo demandará esforços permanentes de servidores da instituição, seja para o agendamento de visitas, para moderação de avaliações ou, ainda, para divulgação das funcionalidades aos alunos e explicação da importância da participação de cada discente.

\section{Considerações finais}

Por meio deste estudo, confirma-se a hipótese de que um aplicativo para dispositivos móveis pode ser um recurso de aproximação entre o IF Sudeste MG Campus Rio Pomba e alunos em potencial, consequentemente, demonstrando-se um aliado na redução da evasão. Apresentam-se os fundamentos que nos levam a acreditar nessa capacidade de promover a inclusão antecipada de tais adolescentes no universo do EMI, apresentando, assim, uma proposta para este produto educacional e comunicacional. Vimos apenas uma das possibilidades de aproximação com este público, contudo, sendo ele composto por nativos digitais, essas possibilidades necessariamente incluem tecnologias de comunicação digitais com as quais estes alunos em potencial já estão familiarizados.

Mensurar os resultados do aplicativo sobre o fenômeno da evasão não é uma tarefa simples, pois como se viu, a evasão é um problema complexo e seus índices sofrem 


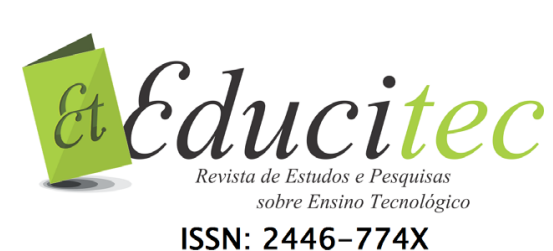

influência de diversos fatores. Todavia, o engajamento dos usuários e o número de downloads, bem como pesquisas com ingressantes que utilizaram o aplicativo, são indicadores possíveis para se aferir o quão eficaz estaria sendo a tecnologia, considerando-se o objetivo de aproximação a que se propõe.

Ademais, não se pode prescindir de uma (re)avaliação periódica que considere possíveis mudanças de hábitos e de mídias adotadas no cotidiano juvenil - um desafio para instituições escolares que se limitam aos próprios muros, desconsiderando a realidade da sociedade de onde vêm seus alunos e impondo a exigência de uma adequação ou adaptação prepotente. Nas palavras de Brenner e Carrano (2014, p. 1237), "o desafio dialógico para educadores e formuladores de políticas educacionais é exercitar a abertura necessária para a incorporação dessas vozes juvenis na arena pública de tomada de decisões relacionadas com a melhoria da escola".

Deixa-se, assim, diretrizes para a criação e disponibilização do aplicativo, na expectativa de um estudo conseguinte, por meio do qual conheça-se a eficácia da presente proposta; mantendo sempre o diálogo como um método sem restrições e, como horizonte, educação pública de qualidade construída por todos e para todos.

\section{Referências}

ALENCAR, Gersica; PESSOA, Maérico dos Santos; SANTOS, Ana Katarine de Freitas Santana; CARVALHO, Solange; LIMA, Hommel Almeida de Barros. Whatsapp como ferramenta de apoio ao ensino. In: Latin American Conference of Learning Objects (LACLO), 2015. Maceió. Anais... do LACLO 2015. p. 787-795.

BARDAGI, Marúcia Patta. Evasão e comportamento vocacional de universitários: estudo sobre desenvolvimento de carreira na graduação. $242 \mathrm{f}$. Tese (curso de Pós-Graduação em Psicologia do Desenvolvimento), Universidade Federal do Rio Grande do Sul. Porto Alegre: 2007.

BARDIN, Laurence. Análise de conteúdo. Tradução Luís Antero Reto e Augusto Pinheiro. São Paulo: Edições 70, 2011.

BRANDÃO, Elizabeth. Conceito de comunicação pública. In: DUARTE, Jorge (Org). Comunicação pública: estado, mercado, sociedade e interesse público. 2ed. São Paulo: Atlas, 2009.

BRANDÃO, Elizabeth. CARVALHO, Bruno. Imagem corporativa: marketing da ilusão. In: DUARTE, Jorge. Assessoria de imprensa e relacionamento com a mídia. São Paulo: Atlas, 2008, p.. 189-205.

BRASIL. Lei n. 8.069, de 13 de jul. de 1990. Estatuto da Criança e do Adolescente. Brasília, DF, jul 1990. Disponível em: <http://www.planalto.gov.br/ccivil_03/LEIS/L8069.htm> Acesso em: 02 Abr. 2019.

BRASIL. Lei 11892, de 29 de dezembro de 2008. Institui a Rede Federal de Educação Profissional, Científica e Tecnológica, cria os Institutos Federais de 


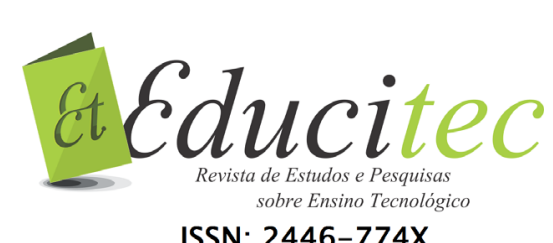

ISSN: 2446-774X

Educação, Ciência e Tecnologia, e dá outras providências. Brasília, DF, dez. 2008 Disponível em: <http://www.planalto.gov.br/ccivil_03/_Ato20072010/2008/Lei/L11892.htm> Acesso em: 22 Abr. 2019.

BRASIL. Lei n. 12.527, de 18 de nov. de 2011. Lei de Acesso à Informação, Brasília, DF, nov 2011. Disponível em: <http://www.planalto.gov.br/ccivil_03/_ato2011-2014/2011/lei//12527.htm> Acesso em: 27 Nov. 2018.

BRENNER, Ana Karina. CARRANO, Paulo Cesar Rodrigues. Os sentidos da presença dos jovens no Ensino Médio: representações da escola em três filmes de estudantes. Educ. Soc., Campinas, v. 35, nº. 129, p. 1223-1240, out.-dez., 2014.

CHINEM, Rivaldo. Comunicação empresarial: teoria e o dia-a-dia das Assessorias de Comunicação. Vinhedo, SP: Horizonte, 2006.

CRESCE número de crianças e adolescentes que buscam notícias na Internet, aponta Cetic.br. Cetic.br, 18 de Set. de 2018. Disponível em: $<$ https://www.cetic.br/noticia/cresce-numero-de-criancas-e-adolescentes-quebuscam-noticias-na-internet-aponta-cetic-br/> Acesso em 04 de abr. de 2019.

DORE, Rosemary; LUSCHER, Ana Zuleima. Permanência e evasão na educação técnica de nível médio em Minas Gerais. Cad. Pesqui., São Paulo, v. 41, n. 144, p. 770-789, Dec. 2011.

DUARTE, Jorge. In: LOPES, Boanerges (Org.). Gestão em Comunicação Empresarial: teoria e técnica. Juiz de Fora: Produtora Multimeios, 2007.

IFS DIGITAL. IFS Digital, 2018. Aplicativo para estudantes do Instituto Federal do Sergipe. Disponível em: $<$ https://play.google.com/store/apps/details?id=br.edu.ifs.ifsdigital\&hl=pt_BR> Acesso em: 04 de abr. 2019.

IF SUDESTE MG. Instituto Federal do Sudeste de Minas Gerais, 2010. Site oficial. Disponível em: <http://www.ifsudestemg.edu.br>. Acesso em: 04 abr. 2019.

IF SUDESTE MG. Pano de Desenvolvimento Institucional. Juiz de Fora, MG, 2014. Disponível em: < http://www.ifsudestemg.edu.br>. Acesso em: $11 \mathrm{de}$ abr. 2019.

IF SUDESTE MG. Plano Estratégico para a Permanência e Êxito dos Estudantes do IF Sudeste MG. Juiz de Fora, MG, 2016. Disponível em: $<$ https://www.ifsudestemg.edu.br/sites/default/files/PLANO\%20PERMANENCIA\%20 E\%20EXITO\%20\%20-\%20final_1_0.pdf>. Acesso em: 29 nov. 2017.

INTERVOZES - COLETIVO BRASIL DE COMUNICAÇÃO SOCIAL. Relatório da Pesquisa Direito à Comunicação no Brasil: Base constitucional e legal, implementação, o papel dos diferentes atores e tendências atuais e futuras. Terceira 
ISSN: 2446-774X

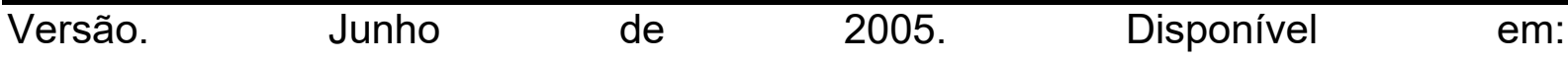
<http://livros01.livrosgratis.com.br/oi000011.pdf>. Acesso em: 22 nov. 2018.

LIMA, Nísia Trindade. Juventude e Ensino Médio: de costas para o futuro? In: FRIGOTTO, G. \& CIAVATTA, M. (orgs.). Ensino médio: ciência, cultura e trabalho. Brasília, MEC/SEMTEC, 2004, 338p.

MINISTÉRIO DA EDUCAÇÃO. Instituto Federal de Educação, Ciência e Tecnologia: concepção e diretrizes. Brasília: 2010. Disponível em: $<$ http://portal.mec.gov.br/index.php?option=com_docman\&view=download\&alias=66 91-if-concepcaoediretrizes\&category_slug=setembro-2010-pdf\&ltemid=30192> Acesso em: 07 de abr. 2019.

MINISTÉRIO DA EDUCAÇÃO. Plataforma Nilo Peçanha, 2019. Ambiente virtual de coleta, validação e disseminação das estatísticas oficiais da Rede Federal de Educação Profissional e Tecnológica. Disponível em: <http://plataformanilopecanha.mec.gov.br/> Acesso em: 07 de Abr. de 2019.

SABOIA, Juliana; VIVA, Marco Aurélio de Andrade; VARGAS, Patrícia Leal de. O uso dos dispositivos móveis no processo de ensino e aprendizagem no meio virtual. Revista Cesuca Virtual: Conhecimento sem fronteiras -, [S.I.], v. 1, n. 1, .2013, Disponível em: <http://ojs.cesuca.edu.br/index.php/cesucavirtual/article/view/424>. Acesso em: 27 nov. 2018.

SILVA, A. Facebook como ferramenta de interação no ensino de informática. Revista de Estudos e Pesquisas sobre Ensino Tecnológico (EDUCITEC), v. 4, n. 08, 2018, $\quad$ p. $23-39 \quad$ Disponível em: https://sistemascmc.ifam.edu.br/educitec/index.php/teste/article/view/350/182..... Acesso em: 10 de set. 2019.

SILVA, K. José. A prática do ensino superior na identidade discente e docente: como a tecnologia educacional pode reduzir a evasão escolar. In: Qualis Sumaré - Revista Acadêmica Eletrônica $13^{\mathrm{a}}$ e $14^{\mathrm{a}}$ edição, 2016. s/p

TINTO, Vincent. Dropout from higher education: a theoretical synthesis of recent research. Teachers College Columbia University:. Review of Educational Research, Vol. $45, n^{\circ} 1$. Columbia, 1975. p. 89-125 